\title{
Differing physiological and behavioral responses to anthropogenic factors between resident and non-resident African elephants at Mpala Ranch, Laikipia County, Kenya
}

\author{
Sandy Oduor ${ }^{\text {Corresp., } 1}{ }^{,}$Janine Brown ${ }^{2}$, Geoffrey M Macharia ${ }^{3}$, Nicole Boisseau ${ }^{4}$, Suzan Murray ${ }^{5}$, Paul Obade ${ }^{3}$ \\ 1 Research, Mpala Research Centre, Nanyuki, Laikipia, Kenya \\ 2 Center for Species Survival, Smithsonian Conservation Biology Institute, Front Royal, Virginia, United States \\ 3 Department of Environmental Science, Kenyatta University, Nairobi, Nairobi, Kenya \\ 4 Endocrine Lab, Smithsonian Conservation Biology Institute, Front Royal, Virginia, United States \\ 5 Global Health Program, Smithsonian Conservation Biology Institute, WASHINGTON, District of Columbia, United States \\ Corresponding Author: Sandy Oduor \\ Email address: oduorsandy@yahoo.com
}

Background: Heterogeneous landscapes like those of Laikipia County, Kenya consist of a mosaic of landuse types, which may exert differential physiological effects on elephants that occupy and traverse them. Understanding behavioral and physiological states of wild African elephants in response to the challenges of living in human-dominated landscapes is therefore important for conservation managers to evaluate risks imposed by elephants to humans and vice versa. Several conservation physiology tools have been developed to assess how animals respond to both natural and anthropogenic changes, and determine biological impacts. This study investigated how migratory and avoidance behavioral to vehicle presence, and vegetation quality affected fecal glucocorticoid (GC) metabolite (FGM) concentrations in African elephants at Mpala Ranch, Laikipia County, Kenya.

Methods: The study compared adrenal glucocorticoid activity of resident elephants that live within Mpala ( $\mathrm{N}=57)$ and non-resident elephants whose space use patterns overlap several ranches $(\mathrm{N}=99)$ in Laikipia County, Kenya. Fecal samples were collected for a 4-month period between April and August for analysis of FGM concentrations. Behavioral reactions to research vehicles and body condition also were assessed. Satellite images from Terra Moderate Resolution Imaging (MODIS MOD13Q1) were downloaded and processed using Google Earth Engine to calculate a Normalized Difference Vegetation Index (NDVI) as a measure of vegetation quality.

Results: As expected, there was a positive correlation between avoidance behavior to vehicle presence and FGM concentrations in both resident and non-resident elephants, whereas there was an inverse relationship between FGM concentrations and NDVI values. Our study also found a positive influence of age on the FGM concentrations, but there were no relationships between FGM and sex, social group type, herd size, and body condition. However, contrary to our expectations, resident elephants had higher FGM concentrations than non-residents.

Discussion: Findings reveal elephants with stronger avoidance responses to research vehicles and resident elephants with relatively smaller home ranges exhibited higher FGM concentrations within the Mpala Ranch, Kenya and surrounding areas. Higher vegetative quality within the ranges occupied by nonresident elephants in Laikipia may be one reason for lower FGM, and an indication that the non-residents are tracking better forage quality to improve energy balance and reduce overall GC output. Additionally, our study found a positive influence of age, but no other demographic variables on FGM concentrations. 
Finally, adrenal glucocorticoid activity was inversely related to vegetative quality. Our findings can help conservation managers better understand how behavior and environment influences the physiological states of African elephants, and how management intervention might mitigate negative human-elephant interactions. 
1 Differing physiological and behavioral responses to anthropogenic factors between resident

2 and non-resident African elephants at Mpala Ranch, Laikipia County, Kenya

4 Sandy Oduor ${ }^{1, *}$, Janine L. Brown ${ }^{2}$, Geoffrey Macharia ${ }^{3}$, Nicole Boisseau ${ }^{4}$, Suzan Murray ${ }^{5}$, Paul

5 Obade $^{3}$

6

$7 \quad{ }^{1}$ Mpala Research Centre, Nanyuki, Laikipia, Kenya

$8{ }^{2}$ Center for Species Survival, Smithsonian Conservation Biology Institute, Front Royal, Virginia,

9 United States

$10{ }^{3}$ Department of Environmental Science, Kenyatta University, Nairobi, Kenya

$11{ }^{4}$ Endocrine Lab, Survival, Smithsonian Conservation Biology Institute, Front Royal, Virginia,

12 United States

$13{ }^{5}$ Global Health Program, Smithsonian Conservation Biology Institute, WASHINGTON District

14 of Columbia, United States

15

$16 *$ Corresponding author:

17 Sandy Oduor,

18 Mpala Research Centre, P. O. Box 555-10400, Nanyuki, Kenya.

19 Email: oduorsandy@yahoo.com

20

21 


\section{ABSTRACT (500 words)}

23 Background: Heterogeneous landscapes like those of Laikipia County, Kenya consist of a

24 mosaic of land-use types, which may exert differential physiological effects on elephants that

25 occupy and traverse them. Understanding behavioral and physiological states of wild African

26 elephants in response to the challenges of living in human-dominated landscapes is therefore

27 important for conservation managers to evaluate risks imposed by elephants to humans and vice

28 versa. Several conservation physiology tools have been developed to assess how animals respond

29 to both natural and anthropogenic changes, and determine biological impacts. This study

30 investigated how migratory and avoidance behavioral to vehicle presence, and vegetation quality

31 affected fecal glucocorticoid (GC) metabolite (FGM) concentrations in African elephants at

32 Mpala Ranch, Laikipia County, Kenya.

33 Methods: The study compared adrenal glucocorticoid activity of resident elephants that live

34 within Mpala $(\mathrm{N}=57)$ and non-resident elephants whose space use patterns overlap several

35 ranches $(\mathrm{N}=99)$ in Laikipia County, Kenya. Fecal samples were collected for a 4-month period

36 between April and August for analysis of FGM concentrations. Behavioral reactions to research

37 vehicles and body condition also were assessed. Satellite images from Terra Moderate

38 Resolution Imaging (MODIS MOD13Q1) were downloaded and processed using Google Earth

39 Engine to calculate a Normalized Difference Vegetation Index (NDVI) as a measure of

40 vegetation quality.

41 Results: As expected, there was a positive correlation between avoidance behavior to vehicle

42 presence and FGM concentrations in both resident and non-resident elephants, whereas there was

43 an inverse relationship between FGM concentrations and NDVI values. Our study also found a

44 positive influence of age on the FGM concentrations, but there were no relationships between 
45 FGM and sex, social group type, herd size, and body condition. However, contrary to our 46 expectations, resident elephants had higher FGM concentrations than non-residents.

47 Discussion: Findings reveal elephants with stronger avoidance responses to research vehicles

48 and resident elephants with relatively smaller home ranges exhibited higher FGM concentrations

49 within the Mpala Ranch, Kenya and surrounding areas. Higher vegetative quality within the

50 ranges occupied by non-resident elephants in Laikipia may be one reason for lower FGM, and an

51 indication that the non-residents are tracking better forage quality to improve energy balance and

52 reduce overall GC output. Additionally, our study found a positive influence of age, but no other

53 demographic variables on FGM concentrations. Finally, adrenal glucocorticoid activity was

54 inversely related to vegetative quality. Our findings can help conservation managers better

55 understand how behavior and environment influences the physiological states of African

56 elephants, and how management intervention might mitigate negative human-elephant

57 interactions. 


\section{INTRODUCTION}

60 Over the past four decades, there has been a continuous decline in wildlife abundance in

61 and outside of protected areas in sub-Saharan Africa (Craigie et al., 2010), including African

62 elephants (Loxodonta africana) (Wittemyer et al., 2014; Chase et al., 2016). As a result, most

63 large herbivore species continue to experience range reductions and local extirpation (Ripple et

64 al., 2015). Many elephant populations also face threats from anthropogenic disturbances,

65 including poaching, human-elephant conflict, land use changes, and habitat destruction

66 (Wittemyer et al., 2014; Chase et al., 2016; Thouless et al., 2016), which can cause animals to

67 alter movement patterns and/or flee areas in response to human presence (Fahrig, 2007).

68 Behavioral indicators have identified effects of human disturbance in elephants (Kiffner et al.,

69 2014; McComb et al., 2014), which can result in long-lasting behavioral changes, including

70 altered responses to vehicles (Vidya \& Thuppil, 2010). In other studies, movement patterns of

71 wildlife in heterogeneous landscapes have been linked to reproductive success and fitness across

72 spatiotemporal gradients (Dingle \& Drake, 2007; Owen-Smith et al., 2010; Jachowski \& Singh,

73 2015; Rolandsen et al., 2017). In addition, studies of bioenergetics confirm animals that must

74 travel greater distances to find adequate forage have lower fitness owing to decreased net energy

75 intake, and reduced investment in reproduction and tissue maintenance (Pontzer \& Kamilar, 76 2009).

77 African elephant movement patterns vary greatly, with some populations migrating over

78 long distances, while others are more facultative migrants and become area residents (Thouless,

79 1996; Dingle \& Drake, 2007; Purdon et al., 2018). The persistence of elephants in human-

80 dominated landscapes raises important questions about the underlying factors motivating spatial

81 behavior, data that could be used to inform on conservation and management planning to 
82 mitigate negative human-animal interactions (Lima \& Zollner, 1996; Nathan et al., 2008).

83 Foraging resource availability, predation risk, and competition (Fryxell \& Sinclair, 1988; Berger,

84 2004; Polansky et al., 2013; Hopcraft et al., 2014), and more recently, factors related to health

85 and welfare are increasingly viewed as important to shaping animal distribution and movements

86 (Kyale et al., 2011; Goldenberg et al., 2018; Keigwin et al., 2018; Ihwagi et al., 2019).

87 One factor that may be related to changes in spatial distribution of elephants is stress,

88 which occurs when extreme and or prolonged physiological or behavioral adjustments are made

89 in response to adverse environments to maintain homeostasis (Dantzer et al., 2014). The stress

90 response typically involves activation of the hypothalamic-pituitary-adrenal (HPA) axis resulting

91 in the release of GCs from the adrenal cortex (Bale \& Vale, 2004), which helps an animal cope

92 with challenges and is generally adaptive (Wingfield et al., 1998; MacDougall-Shackleton et al.,

93 2019). However, it is well documented that prolonged exposure to stressful conditions and

94 elevated GCs can have negative, non-adaptive consequences, such as inhibition of reproduction,

95 decreased growth rates, and immune suppression leading to increased disease susceptibility and

96 decreased wound healing (Sapolsky et al., 2000; Romero \& Wingfield, 2015). That said, it is

97 important to note that GCs play an essential role in general energy metabolism, and are involved

98 in normal physiological function as well (Strack et al., 1995; Busch \& Hayward, 2009). In

99 elephants, GCs increase during the follicular phase of the estrous cycle, pregnancy and

100 parturition (Brown \& Lehnhardt, 1995; Fanson et al., 2014). Thus, it is important to take

101 biological context into account when relying on GC measures to evaluate stress and welfare.

102 The use of fecal samples to assess physiological responses to stressors, both positive and

103 negative, via GC metabolite (FGM) analyses has become an important conservation tool to

104 understand how animals respond to internal states and external environmental conditions 
105 (Bradshaw, 2007; Denver et al., 2009; Soares et al., 2010; Ganswindt et al., 2012). FGM

106 monitoring has several advantages in that samples can be collected with minimal disturbance to

107 the animal (Harper \& Austad, 2001) and concentrations reflect pooled values over hours rather

108 than a specific point in time, making them a better measure of overall adrenal activity (Sheriff et 109 al., 2011).

110 The physiological demands of ranging over long distances can expose animals to stressful

111 environments, making them more susceptible to disturbance (Wilcove \& Wikelski, 2008).

112 Negative influences of poaching, human-wildlife conflict, habitat loss, and population

113 fragmentation can affect the physiology of elephants, including reduced reproductive output and

114 increased FGM concentrations (Foley et al., 2001; Gobush et al., 2008; Graham et al., 2009;

115 Hunninck et al., 2017; Vijayakrishnan et al., 2018). FGM concentrations also have been linked

116 to space use patterns in elephants; i.e., the spatial refuge hypothesis, which predicts higher stress

117 in animals with more restricted space compared to those with wider land use patterns (Viljoen et

118 al., 2008; Jachowski et al., 2012; Jachowski et al., 2013). Finally, studies have shown that some

119 wild African elephant populations exhibit higher FGM concentrations outside of protected areas

120 (Tingvold et al., 2013; Hunninck et al., 2017; Vijayakrishnan et al., 2018), although not all

121 (Ahlering et al., 2013).

122 This study examined FGM concentrations of elephants that utilize the Mpala Ranch, a 200

$123 \mathrm{~km}^{2}$ privately owned cattle ranch in the semi-arid savanna of Laikipia County, Kenya. Wildlife

124 conservation on private ranches can play an integral role in ensuring the persistence of large

125 mammals on land occupied by humans and livestock (Hunt, 1997; Figgis, 2004; Cousins et al.,

126 2008; Sundaresan \& Riginos, 2010). This is in contrast to communal ranches where livestock

127 concentrations are high, lethal methods are used to control wildlife, and human populations are 
128 increasing (Kinnaird \& O'brien, 2012). Laikipia County is a non-protected savannah region

$129\left(9,666 \mathrm{~km}^{2}\right)$ located on the equator that is divided into a mosaic of privately, publicly and

130 communally owned ranches (LWF, 2012). Elephants within the Laikipia-Samburu ecosystem

131 inhabit a wide variety of land uses with varying degrees of human occupation and disturbance

132 (Graham et al., 2009; Kahindi et al., 2010), and little is known about how that affects ranging

133 patterns and adrenal activity. Although the population has been increasing over the years

134 (Omondi et al., 2002; Litoroh et al., 2010; Ngene et al., 2013), Laikipia County has experienced

135 land cover changes over the past three decades due to climate change and anthropogenic

136 activities (M'mboroki et al., 2018), which may influence forage quality and elephant physiology.

137 Thus, this study also examined how normalized difference vegetation index (NDVI) - a measure

138 of forage availability based on the amount of red and near-infrared light from the earth surface

139 (Pettorelli et al., 2005) potentially influences FGM concentrations in resident and non-resident

140 African elephants at Mpala. We hypothesized that 1) resident elephants with relatively smaller

141 ranges on the private Mpala Ranch will have lower FGM concentrations than non-resident

142 elephants due to high levels of human disturbance outside of Mpala; 2) elephants exhibiting

143 avoidance behavior to research vehicles will excrete more FGM due to differences in coping

144 strategies to environmental stressors; and 3) vegetative quality, measured as NDVI, will be

145 inversely related to FGM concentrations due to higher nutritional stress during the dry season.

146 This study also explored potential correlations between FGM and body condition, and a number

147 of social and demographic variables, including sex, social group type (mother with calf, bulls,

148 mixed male/female group), age group (juvenile, sub-adult, adults), and number of individuals in

149 the herd, all of which have been shown to correlate with HPA activity in elephants and other

150 mammals (Foley et al., 2001; Huber et al., 2003; Rasmussen et al., 2008). Understanding the 
151 links between ranging behavior, environmental quality, and the physiological state of elephants

152 is important to monitoring elephant aggression towards people and increased levels of conflict in

153 human-occupied landscapes for management interventions and species conservation.

\section{MATERIALS \& METHODS}

\section{Study area}

156 A map of the Mpala Ranch is shown in Figure 1. It is a private landholding of $200 \mathrm{~km}^{2}$ that

157 supports wildlife conservation with limited livestock production. The property is not fenced and

158 is surrounded by other private and communal ranches with differing degrees of wildlife

159 tolerance. Mpala Ranch lies north of the equator on the Laikipia plateau (latitude, $0^{0} 17^{\prime} 32^{\prime \prime} \mathrm{N}$;

160 longitude, $36^{0} 53^{\prime} 52$ '” E). Rainfall at Mpala Ranch averages $\sim 600 \mathrm{~mm}$ per year in a weakly tri-

161 modal annual pattern with a short dry season from December - March and peak rainfall in April

162 - May and August - October (Augustine \& McNaughton, 2004; Pringle, 2008; Goheen et al.,

163 2013). The study area is characterized by woody vegetation, with Acacia drepanolobium being

164 monodominant in black cotton vertisol soil (Young et al., 1997) and Acacia brevispica, Acacia

165 mellifera, and Acacia etbaica species dominating the alfisol soil (Pringle et al., 2016). Other

166 woody species include Croton dichogamous, Rhus vulgaris and Grewia species (Young et al.,

167 1995). Although African elephants are general feeders, dietary preferences are dependent on

168 season (Codron et al., 2006; Kartzinel et al., 2019), and movement behavior at Mpala Ranch is

169 mainly influenced by woody cover, seasonal forage and water availability, and presence of

170 human settlement and cattle bomas (Ochieng, 2015). In addition to African elephants, Mpala

171 Ranch also is home to threatened lions (Panthera leo), leopards (Panthera pardus), cheetahs

172 (Acinonyx jubatus), and endangered African wild dogs (Lycaon pictus). The area supports a 
173 number of large herbivores, including the endangered Grevy's zebras (Equus grevyi) and

174 threatened reticulated giraffe (Giraffa camelopardalis).

175 Between 2009 and 2014, an elephant monitoring program was conducted to understand

176 how elephants use Mpala Ranch, assess their demographic characteristics (Ochieng, 2015), and

177 determine proportions of resident versus non-resident families. Elephants are individually

178 identified by ear and tusk features (Douglas-Hamilton, 1972; Moss, 1996) and classified as

179 residents or non-residents based on the temporal use patterns (i.e. shift in abundance and degree

180 of residency) throughout the ranch. Non-resident elephants are those that are observed

181 intermittently at Mpala Ranch. Their movement in and out of Mpala Ranch is unpredictable,

182 although in general they stay in the area between 3-5 months a year depending on vegetation

183 quality and water levels around the dams at Mpala. Elephant home ranges typically overlap

184 multiple communal and private conservancies within Laikipia (Thouless, 1993), whereas resident

185 elephants are restricted to Mpala Ranch.

\section{Data collection}

187 A demographic summary of the study elephants at Mpala Ranch is shown in Table 1. Fecal

188 samples and behavioral data were conducted between 23 April (toward the end of the dry season)

189 and 30 August 2019 (toward the beginning of the short wet season). A pictorial database of the

190 catalog recognition file developed by the Mpala Elephant Research Project was uploaded onto a

191 Samsung Galaxy Tablet (T580 10.1) and used in the field for individual elephant identification.

192 In the event that a new family group, lone bull or bachelor group were encountered, photos were

193 taken using the method described by Moss (1996) and incorporated into the database. Examples

194 of elephants in the catalog recognition file are shown in Figures S1 and S2. 

as through communications with security outposts throughout Mpala. When elephants were encountered, the behavioral reaction to the observer vehicle (i.e. reaction index) was categorized as follows: 1) nonresponsive within $20 \mathrm{~m}$ of vehicle approach (i.e., the activity of the family group or individual was not interrupted by approach of the vehicle within $20 \mathrm{~m}$ ); 2) retreating by walking more than $20 \mathrm{~m}$ away from vehicle approach (i.e., the activity of the family group or individual was slightly interrupted by approach of the vehicle within $20 \mathrm{~m}$ but the elephants remained calm for at least 10 seconds); or 3) retreating by running more than $20 \mathrm{~m}$ away from vehicle approach (i.e., the activity of the family group or individual was interrupted by the vehicle, and individuals responded by whipping the trunk or flapping its ears before running while vocalizing with tail raised). The vehicle's engine was then turned off and individuals were observed from a distance until defecation occurred. In the event an individual or family group ran more than $100 \mathrm{~m}$ from the vehicle or into a dense Acacia thicket and were out of visual range, no fecal samples were collected. Time of defecation, time of sample collection, sex, age group (juvenile $=0-8 \mathrm{yr}$; sub-adult $=9-17 \mathrm{yr}$; adult $>18 \mathrm{yr}$ ), social group (mother with calf,

210 solitary bull, bachelor group, mixed male/female group), ranging behavior (resident or migrant),

211 presence of temporal gland secretion in bulls, and number of individuals in the herd were

212 recorded based on Moss (1996). A body condition score (BCS) also was assigned using a 5-point

213 scale developed for African elephants (Morfeld et al., 2014) with 1 representing very thin and 5

214 representing very fat. The coordinates where dung samples were collected were recorded using a

215 Garmin 63 hand-held Global Positioning System.

\section{Assessment of vegetation quality}


217 Vegetation quality within Mpala Ranch was assessed using a Terra Moderate Resolution

218 Imaging Spectroradiometer (MODIS, MOD13Q1) that generated images every 16 days at a 250

219 m spatial resolution. Data were used to calculate NDVI (Carroll et al., 2004), a ratio of the near-

220 infrared and red reflectance spectral bands that are reflected and captured by a satellite's sensor

221 and scaled between 1 (which indicates green vegetation) and -1 (which indicates no vegetation)

222 (Pettorelli et al., 2005). NDVI layers from MOD13Q1 were generated for the period between 23

223 April 2019 and 30 August 2019 to reflect the vegetation productivity and potential nutritional

224 quality during the study. To account for phenological variation within the collected reference

225 data, each fecal sample was linked to the NDVI data point for every location that had the closest

226 available date. First, all the 156 coordinates represented by 156 fecal points were loaded onto the

227 code editor (java) interface of Google Earth Engine (GEE). Satellite images were extracted

228 online (https://pdaac.usgs.gov/products/mod13q1v006) and defined to within Mpala where the

229 fecal samples were spatially distributed. The satellite images were then filtered by masking

230 pixels with cloud cover greater than $10 \%$ using the GEE simple cloud score function. Clouds,

231 aerosol loading, shadows and other outliers, are known to affect the NDVI values and as a result

232 removed using Savitzky-Golay smoothing filter (Beltran-Abaunza, 2009). NDVI was then

233 calculated using the following equation: (near-infrared band - red band)/ (near-infrared + red

234 band). An NDVI chart panel for all the 156 points were then created based on the date of

235 collection. Additionally, satellite images from Landsat 8 were mosaicked and clipped to within

236 Laikipia County and also clipped to within Mpala Ranch. The annual 2019 NDVI base layer map

237 for Laikipia and Mpala was compared as shown in Figure S3.

238 Fecal sample collection, processing and FGM analysis 
239 One fecal samples was collected from 156 uniquely identified elephants within $2-30$ minutes of

240 defecation and stored in an insulated box with ice packs in the field. To account for variation in

241 concentrations of FGM among and within dung samples, at least two boli were broken open and

242 subsamples taken from the interior part (Ganswindt et al., 2005). Samples were placed into 60-

$243 \mathrm{ml}$ plastic tubes and labelled with a unique number, the date and family ID. Time from

244 defecation to when samples were placed in a cool box in the field was recorded for each sample.

245 Samples were then transferred to a $-80^{\circ} \mathrm{C}$ freezer at the Mpala Ranch within 6 hours of 246 defecation.

247 Fecal samples were extracted based on Wasser et al. (2000) at the Mpala Research Center

248 Endocrinology Laboratory. Frozen samples were thawed, mixed thoroughly, and $0.50 \pm 0.02 \mathrm{~g}$

249 extracted with $90 \%$ methanol in a $16 \times 100 \mathrm{~mm}$ glass tube by vortexing for 30 minutes and then

250 centrifuging at $1,800 \mathrm{~g}$ for 20 minutes. The supernatants were decanted into another set of $16 \mathrm{x}$

$251100 \mathrm{~mm}$ tubes and dried under air in a warm water bath. Dried extracts were reconstituted with 1

$252 \mathrm{ml}$ of assay buffer (Cat. No. X065, Arbor Assays, Ann Arbor, MI USA) and sonicated until

253 completely re-suspended, then frozen at $-20^{\circ} \mathrm{C}$ until analysis.

254 Extracts were diluted 1:4 in assay buffer and analyzed in duplicate for FGM concentrations

255 using a double-antibody corticosterone enzyme immunoassay (EIA) (Arbor Assays, Cat. No.

256 K014-H5) with no modifications. Optical density was determined using a plate reader (Thermo

257 Scientific Multiskan FC) at $450 \mathrm{~nm}$, and FGM concentrations were calculated using the

258 sigmoidal dose response program (www.myassay.com). The EIA was validated for elephants by

259 demonstrating parallelism between serial extract dilutions and the standard curve $(y=1.03 \mathrm{x}+$

$2605.13, \mathrm{r}=0.97)$, and excellent recovery of unlabeled corticosterone standard added to a low

261 concentration sample $(y=0.95 x+49.25, r=0.99)$. A graph of parallelism and recovery curves 
262 are shown in Figures S4 and S5 respectively. Biological validity was demonstrated by showing

263 significant increases in FGM in an elephant 2 days before euthanasia for declining health $(9.33$

$264 \mathrm{ng} / \mathrm{g}, \mathrm{n}=1)$ compared to pre-illness baseline $(2.32 \pm 0.14 \mathrm{ng} / \mathrm{g}, \mathrm{n}=10)$, before $(1.19 \pm 0.10 \mathrm{ng} / \mathrm{g}$,

$265 \mathrm{n}=12)$ and in the days after $(3.72 \pm 0.14 \mathrm{ng} / \mathrm{g}, \mathrm{n}=2)$ a tail injury, and before $(1.28 \pm 0.16 \mathrm{ng} / \mathrm{g}$,

$266 \mathrm{n}=6)$ and in the first week of a bout of lameness ( $3.72 \pm 0.13 \mathrm{ng} / \mathrm{g}, \mathrm{n}=3)$. FGM concentrations

267 using the Arbor Assays EIA also were correlated with samples analyzed by a previously

268 validated corticosterone EIA (Watson et al., 2013) $(\mathrm{r}=0.94, \mathrm{n}=40)$ and corticosterone

269 radioimmunoassay (Wasser et al., 2000) $(\mathrm{r}=0.92, \mathrm{n}=30)$. Based on our laboratory criteria, any

270 duplicate with a coefficient of variation (CV) $>10 \%$ or plate where the control CVs exceeded

$27115 \%$ of the control monitor were reanalyzed. In this study, no plates were redone and duplicates

272 reruns were $<5 \%$. The EIA sensitivity was $0.90 \mathrm{pg} /$ well (at $90 \%$ binding), and intra- and inter-

273 assay coefficients of variation of high and low controls were $3.98 \%$ and $8.26 \%$ ( $n=7$ plates),

274 respectively. Extraction and EIA analyses were carried out over a 3-week period starting 60 days

275 after completion of fecal sample collection at the Mpala Research Center.

\section{Data analysis}

277 FGM values were log-transformed to obtain a normal distribution of the model residuals. Linear

278 regression model was used in constructing our model. Ranging behavior, reaction index and

279 NDVI were included in our basic model while the effect of each of the additional factor was

280 included in the basic model to determine whether additional variables influenced FGM

281 concentrations. Model selection was then done by comparing the basic model with the models

282 consisting of both the basic model and additional factors that could be influencing FGM

283 concentrations in African elephants. To discern differences in FGM concentrations among

284 different factor variables emmeans package (Lenth et al., 2018) was used. The competing models 
285 generated were ranked using $\triangle \mathrm{AICc}<2$. (Akaike's Information Criterion adjusted for small 286 sample sizes; (Burnham \& Anderson, 2002) to determine the model that was a better fit to the 287 data in MuMin package. The basic model was then validated by plotting the results of the model 288 to visually check for normality of the residuals, homogeneity, and the presence of outliers in the 289 model (Fig. S6). Back-transformed model estimates were plotted to illustrate predicted response values and show relationships between the fitted response values and the predictor variables.

291 Mean data are expressed as \pm SD. Data were analyzed in R version 3.5.1 (R Development Core 292 Team, 2018).

\section{RESULTS}

Overall FGM concentrations $(\mathrm{N}=156)$ averaged $5.92 \pm 2.15 \mathrm{ng} / \mathrm{g}$ with individual FGM ranging from 2.58 to $15.55 \mathrm{ng} / \mathrm{g}$. FGM concentrations differed between sexes with females (6.30 $\pm 2.43 \mathrm{ng} / \mathrm{g}, \mathrm{N}=81)$ having higher concentrations than males $(5.51 \pm 1.73 \mathrm{ng} / \mathrm{g}, \mathrm{N}=75)$. Mean FGM concentrations were higher in adults $(6.28 \pm 2.28 \mathrm{ng} / \mathrm{g}, \mathrm{N}=82)$ compared to juveniles $(5.61 \pm 1.63 \mathrm{ng} / \mathrm{g}, \mathrm{N}=43)$ and sub-adults $(5.39 \pm 2.32 \mathrm{ng} / \mathrm{g}, \mathrm{N}=31) . \mathrm{FGM}$ concentrations also varied among social group types with mothers with calf $(6.22 \pm 2.23 \mathrm{ng} / \mathrm{g}, \mathrm{N}=103)$ having higher concentrations compared to bull groups $(5.59 \pm 2.37 \mathrm{ng} / \mathrm{g}, \mathrm{N}=15)$ and mixed male/female groups $(5.23 \pm 1.68 \mathrm{ng} / \mathrm{g}, \mathrm{N} 38)$. FGM concentrations varied by BCSs with BCS $=2$ exhibiting higher FGM concentrations $(6.90 \pm 2.81 \mathrm{ng} / \mathrm{g}, \mathrm{N}=18)$ compared to those with $\mathrm{BCS}=$

$3(5.99 \pm 2.14 \mathrm{ng} / \mathrm{g}, \mathrm{N}=96)$ or $\mathrm{BCS}=4(5.33 \pm 1.69 \mathrm{ng} / \mathrm{g}, \mathrm{N}=42)$. There also was a difference

304 in behavioral responses to vehicle presence between resident and non-resident elephants $\left(\chi^{2}=\right.$ 22.13, $\mathrm{df}=1, \mathrm{p}=2.55^{-06}, \mathrm{~N}=78$ ) with non-residents reacting negatively to vehicle presences 
307 0.07), while April had the lowest $(0.295 \pm 0.11)$ (Fig. S7). Additionally, Laikipia County overall

308 had relatively higher NDVI compared to Mpala Ranch (Fig S5).

309 Our study found support for three models: the basic model that included factors related to

310 ranging behavior, the behavioral reaction index and NDVI, and two models consisting of

311 additional factors that might affect FGM, which were age (juvenile $=0-8 \mathrm{yr}$; sub-adult $=9-17 \mathrm{yr}$;

312 adult $>18 \mathrm{yr}$ ) and social groups (mother with calf, solitary bull, bachelor group, mixed

313 male/female group). There was, however, no influence of body condition, sex, herd size and time

314 delay on FGM concentrations (Table 2).

315 In support of our hypothesis, ranging behavior, reaction index, and NDVI were all found

316 to influence FGM concentrations $\left(\mathrm{F}_{4,151}=9.4262, \mathrm{p}<0.0001\right)$. Resident elephants exhibited

317 significantly higher FGM concentrations $(5.84 \pm 0.5 \mathrm{ng} / \mathrm{g}, \mathrm{CI}=5.27-6.48 \mathrm{ng} / \mathrm{g})$ compared to

318 non-resident elephants $(5.21 \pm 0.6 \mathrm{ng} / \mathrm{g}, \mathrm{CI}=4.60-5.89 \mathrm{ng} / \mathrm{g})$, while concentrations were higher

319 among individuals that retreated by running more than $20 \mathrm{~m}$ away from vehicle approach $(6.07 \pm$

$3200.5 \mathrm{ng} / \mathrm{g}, \mathrm{CI}=5.54-6.65 \mathrm{ng} / \mathrm{g})$ compared to those that were nonresponsive $(5.21 \pm 0.6 \mathrm{ng} / \mathrm{g}, \mathrm{CI}$

$321=4.60-5.89 \mathrm{ng} / \mathrm{g})$ or retreated by walking more than $20 \mathrm{~m}$ away from vehicle approach $(4.99 \pm$

$3220.4 \mathrm{ng} / \mathrm{g}, \mathrm{CI}=4.61-5.40 \mathrm{ng} / \mathrm{g})$. Model results also showed an inverse relationship between

323 predicted FGM concentrations and NDVI values (Fig. 2), with higher FGM concentrations

324 observed when vegetation quality was low during the dry season $(10.04 \pm 1.6 \mathrm{ng} / \mathrm{g}, \mathrm{CI}=7.38-$

$32513.64 \mathrm{ng} / \mathrm{g})$ compared to the wet season $(4.23 \pm 0.8 \mathrm{ng} / \mathrm{g}, \mathrm{CI}=3.63-4.92 \mathrm{ng} / \mathrm{g})$ when Mpala had

326 higher vegetation quality. Only age was found to be an additional factor influencing FGM

327 concentrations $\left(\mathrm{F}_{6,149}=7.6143, \mathrm{p}<0.0001\right)$. Although the addition of social group was a better

328 model fit for the data $\left(\mathrm{F}_{6,149}=7.4191, \mathrm{p}<0.0001\right)$ than the basic model, it did not significantly

329 affect FGM concentrations in the study population (Table 3). 


\section{DISCUSSION}

331 This is the first study to examine FGM concentrations in elephants living within the Laikipia

332 county of Kenya and found relationships between FGM and migratory patterns, behavioral

333 responses to vehicle approach, and vegetative quality. As predicted, elephants exhibiting

334 avoidance responses to research vehicles had higher FGM concentrations. Similarly, higher

335 FGM concentrations were found when vegetation quality, based on NVDI, was low. However,

336 contrary to our expectations, resident elephants exhibited higher FGM concentrations compared

337 to non-resident elephants, which may be related to higher vegetative quality in areas outside of

338 Mpala Ranch before the onset of the wet season, or a variety of human activities in the region.

\section{Influence of ranging behavior on FGM}

340 Based on other studies, we hypothesized that resident elephants with small home ranges would

341 exhibit lower adrenal GC activity than long-distance migrants (Wilcove \& Wikelski, 2008;

342 Pontzer \& Kamilar, 2009; Wittemyer et al., 2017). With the Laikipia-Samburu ecosystem

343 experiencing high levels of poaching between 2007 and 2012, elephants have been observed to

344 alter their circadian rest patterns in response to human activities (Wittemyer et al., 2017),

345 increase their speed while traversing through risky landscapes (Douglas-Hamilton et al., 2005),

346 and shift movement patterns to be more active at night (Ihwagi et al., 2018). So we expected to

347 observe higher FGM concentrations among the non-resident elephants. However, the opposite

348 was true - resident elephants had higher FGM concentrations than non-residents. One reason

349 could be exposure of resident elephants to higher levels of human activities in the northern part

350 of Mpala. Earlier, Awuor (2015) observed a negative influence of military activities on the

351 distribution and abundance of wildlife at Mpala. This training, primarily carried out in the north,

352 involves drills and use of fire arms and explosives, which could have resulted in higher FGM 
353 concentrations in residents. In addition, the harassment of elephants by cattle herders around

354 dams, particularly during the dry season when conflict over water resources is high, also could

355 have affected adrenal steroid activity during the study period. Alternatively, elephants could have

356 been responding to research vehicles and vehicular traffic along an arterial public road which

357 cuts through Mpala Ranch, and if viewed as a threat could have resulted in higher FGM. Finally,

358 our results lend support to the spatial refuge hypothesis, which predicts higher FGM

359 concentrations in animals with more restricted space compared to those with wider land use

360 patterns (Viljoen et al., 2008; Jachowski et al., 2012; Jachowski et al., 2013). Several studies

361 have observed significant effects of human disturbances on FGM concentrations in elephants

362 (Gobush et al., 2008; Jachowski et al., 2012; Tingvold et al., 2013; Haase et al., 2016; Hunninck

363 et al., 2017; Vijayakrishnan et al., 2018), and so all of these theories warrant further

364 investigation.

365 Jachowski et al. (2018) observed the effects of high forage quality tracking and the use of

366 stopover sites on the FGM concentrations of mule deer. Although elephant home ranges are

367 restricted to both artificial and permanent water sources during the dry season (Chamaillé-

368 Jammes et al., 2013; Purdon \& Van Aarde, 2017), they are known to track peak forage quality

369 (Loarie et al., 2009) to improve their energy balance which could have resulted in lower FGM

370 concentrations in non-resident elephants at Mpala Ranch. Although the physiological demands of

371 ranging over long distances exposes animals to stressful environments (Wilcove \& Wikelski,

372 2008), access to better forage quality could act as a potential 'pacifier' against stress (Pokharel et

373 al., 2019) which then leads to lower FGM concentrations among non-resident elephants.

374 Shaw \& Couzin (2013) posited that residency or non-residency behavior in animals is

375 selected for when distribution of resources is dominated by local patchiness. Elephants are 
376 known to switch diets depending on seasonality (Kartzinel et al., 2019) and land use. Vegetative

377 changes have occurred in Laikipia to a present day mosaic of grassland and Acacia bushland

378 habitats (Taylor et al., 2005), and mixture of extensive agriculture, pastoralism and wildlife

379 areas. Differences in FGM concentrations of elephants at Mpala Ranch could be attributed to

380 non-residents having access to higher quality diets due to greater foraging, resulting in lower

381 FGM concentrations. In India, (Pokharel et al., 2019) also observed lower FGM concentrations

382 among crop raiding elephants, which was speculated to act as a mitigator against stress compared

383 to elephants in protected forests with limited calorie-dense food sources.

384 Relationships between behavioral responses and FGM

385 Results from our model revealed higher FGM concentrations in elephants that ran away from

386 vehicle presence compared to those that were either nonresponsive or retreated slowly. However,

387 although resident elephants exhibited higher FGM concentrations in general, the majority were

388 either nonresponsive to or slowly retreated from vehicle presence compared to non-residents that

389 generally retreated or ran. Studies have shown an influence of spatial knowledge and cognitive

390 behavior on movement decisions of African elephants (Polansky et al., 2015). The difference in

391 behavioral reactions could have been due to resident elephants being more habituated to research

392 vehicles and not perceiving them as a threat and hence they did not respond as dramatically as

393 non-residents. Older elephants retain memories of negative historical events (Soltis et al., 2014),

394 which may disproportionately influence the behavior of the group (McComb et al., 2001).

395 Goldenberg et al. (2017) observed differences in behavioral responses to vehicle presence

396 between resident and non-resident elephants in Samburu and Buffalo Spring National Reserve in

397 northern Kenya due to repeated exposure of resident elephants to researchers and tourist

398 vehicles. Mpala Ranch also supports a number of activities with higher vehicular traffic from 
399 researchers and an arterial public road compared to neighboring conservancies, which could have

400 influenced behavioral responses between resident and non-resident elephants at Mpala. It is

401 important to note, however, that FGM is a measure of GC metabolite accumulation over 1-2 days

402 prior to excretion, so we are not measuring real-time responses to vehicle presence, but rather the

403 adrenal GC state of elephants that are more or less reactive using vehicle presence as a proxy.

404 The landscape of fear paradigm is an important mechanism related to the spatial ecology

405 of animals across heterogeneous landscapes (Gallagher et al., 2017). The process by which an

406 animal collects, stores and interprets environmental information not only influences their

407 decision-making process, but also their behavior, physiology and life history (Lima \& Dill,

408 1990). In other ungulates including elephants, studies have shown animals alter behavior by

409 increasing flight distance in response to vehicles, human harassment or hunting (Stankowich,

410 2008; Tarakini et al., 2014; Ranaweerage et al., 2015; Szott et al., 2019), so the higher FGM

411 concentrations could have been as a result of anthropogenic disturbance. Behavioral changes and

412 increased physiological stress have also been observed in African elephants in response to

413 disturbances caused by wildlife tourism (Szott et al., 2020). Finally, negative impacts on the

414 behavioral response of wild Asian elephants to roads, vehicular traffic, and presence of heavy

415 trucks have been observed in Asian elephants in Mudumalai Wildlife Sanctuary (Gubbi et al.,

416 2012; Wadey et al., 2018). Only small, four-wheel-drive vehicles were used in this study, which

417 approached slowly to within $20 \mathrm{~m}$ of the closest elephant. Again, with a gut transit time of $\sim 48 \mathrm{hr}$

418 (Wasser et al., 2000), immediate responses to vehicle presence would not be reflected in FGM

419 concentrations. Even still, individuals exhibiting stronger avoidance behavior had higher FGM

420 concentrations, an indication that negative behavioral reactivity to vehicle presence could be

421 related to higher adrenal activity overall. Negative effects of increased human population growth 
422 and pastoral settlements on wildlife distribution (Ogutu et al., 2010), and the recent subdivision

423 and sedentarization of pastoral lands in savanna ecosystems that support livestock and wildlife

424 (Western et al., 2009) shows there is need for both endocrine and behavioral monitoring to

425 determine how human activities affect the stress physiology and fitness of wildlife.

426 Influence of NDVI on FGM

427 Results from our model found an inverse relationship between FGM concentrations and NDVI at

428 Mpala Ranch with both resident and non-resident elephants experiencing higher FGM

429 concentrations when NDVI was low compared to when it was relatively high. Studies have used

430 NDVI as a proxy for forage quality and dietary protein (Hamel et al., 2009; Petorelli et al., 2011;

431 Stabach et al., 2015; Hunninck et al., 2020), and its use to assess forage quality in relation to

432 FGM concentrations in wildlife is on the rise. For instance, (Stabach et al., 2015) observed an

433 inverse relationship between FGM concentrations and NDVI in wildebeest in Kenya. Pokharel et

434 al. (2019) also confirmed an inverse proportionality between FGM concentrations and NDVI in

435 free-ranging Asian elephants in India, while Hunninck et al. (2020) found an inverse relationship

436 between FGM concentrations and NDVI in impalas in the Serengeti ecosystem. Our study was

437 limited by having fewer samples collected during the dry season (end of April to mid-May);

438 nevertheless, our findings confirm the influence that vegetation quality potentially has on the

439 adrenal response of wildlife. The fact that migrant elephants had lower FGM concentrations than

440 residents suggests they may be tracking vegetation quality to improve bioenergetics. A wide-

441 ranging foraging strategy may better meet nutritional demands (Parker et al., 2009; Sach et al.,

442 2019), thus reducing GC output.

\section{Other factors influencing FGM}


444 Our study found a relationship between FGM and age group, with adults exhibiting higher FGM

445 concentrations than other age categories, similar to what was observed in free-ranging Asian

446 elephants (Vijayakrishnan et al., 2018). This could be due to increased responsibilities and other

447 leadership roles adults play within the herd (McComb et al., 2011). However, other studies have

448 found no clear relationship between FGM concentrations and age in free ranging elephants in

449 other parts of Africa (Ganswindt et al., 2005; Viljoen et al., 2008). From our model, the variable

450 social group type did not influence FGMs, although mothers with calves did exhibit significantly

451 higher FGM concentrations compared to mixed groups. The high FGM concentrations in

452 mothers with a calves could be attributed to their increased level of 'awareness' in heterogeneous

453 landscapes and areas that pose higher poaching risks or dangers to the calves (Boettiger et al.,

454 2011), and their role in caring for other calves (allomothering) in the herd (Lee, 1987). Other

455 authors have also found a positive relationship between lactating mothers and FGM

456 concentrations in free-ranging Asian elephants (Pokharel et al., 2020). Otherwise, there were no

457 differences in FGM concentrations between mothers with calves and bulls or between bulls and

458 mixed groups.

459 Sex differences in hypothalamo-pituitary-adrenal responses have been observed in multiple

460 species, and may be related to social and physiological factors (Creel et al., 2013). In elephants,

461 some studies have found higher FGM concentrations in females than males (Hunninck et al.,

462 2017), while others show the reverse (Ahlering et al., 2013), and there are additional examples of

463 no differences between the sexes (Munshi-South et al., 2008; Tingvold et al., 2013). Our data

464 agree with the latter, with no significant difference in FGM concentrations between sexes. Thus,

465 whether physiological or behavioral variation explains sex differences, or if it is due to other

466 extrinsic factors, remains to be determined. 
Although our model found no influence of BCS on adrenal activity in the elephants at

468 Mpala Ranch, individuals with lower BCSs had relatively higher mean FGM concentrations

469 compared to individuals with higher scores. Low BCS has been associated with nutrient-

470 deficient diets and resource limitations, resulting in increased protein catabolism and muscle

471 deterioration, and subsequently elevated stress levels (Harvey et al., 1984). In a study of wild

472 Asian elephants, a similar relationship between high FGM and low BCS was found and thought

473 to be due to seasonal shifts in diet quality (Pokharel et al., 2017). Finally, Mumby et al. (2015)

474 observed seasonal changes in body weight and FGM of logging elephants in Myanmar related to

475 rainfall (body weight) and the work period (FGM). In our study, data were only collected for 4

476 months, so it is possible a longer collection period would reveal clearer relationships between

477 body condition and adrenal function.

478 African elephants exhibit a fission-fusion social society (Douglas-Hamilton, 1972; Moss \&

479 Poole, 1983; Wittemyer et al., 2005; Couzin, 2006), with benefits of congregating in large

480 groups include cooperative defense of calves, and shared social and ecological knowledge from

481 older, more experienced herd members (Dublin, 1983; McComb et al., 2001). However, our

482 study found no relationships between social group size and FGM concentrations, or the overall

483 response to vehicle presence. This study also did not find any relationship between herd size and

484 FGM concentrations in relation to NDVI. Thus, while other studies have found higher FGM

485 concentrations associated with larger herd sizes, particularly during the dry season (Foley et al.,

486 2001), our study was only conducted for 4 months, so additional annual analyses are needed.

487 The influence of time delay between defecation and sample stabilization via freezing on the

488 degradation of hormone metabolite concentrations is an important consideration (Möstl \& Palme,

489 2002). Hunninck et al. (2017) found a slight increase in FGM concentrations with increasing 
490 time delay, at about 2 hours post defecation in African elephants. Webber et al. (2018)

491 determined that hormone degradation starts to occur at about 20 hours after defecation in African

492 elephants. All samples in our study were collected within 30 minutes after defecation and placed

493 in a cold box before being frozen within 6 hours, so it was not surprising there was no

494 relationship between FGM concentrations and delay time.

\section{CONCLUSIONS}

496 This study found that elephants with strong avoidance responses to research vehicles and

497 resident elephants with relatively smaller ranges exhibited higher FGM concentrations within the

498 Mpala Ranch in Kenya. This information is important and can inform policy makers like the

499 Kenya's National Elephant Management and Conservation Strategy and conservation managers

500 on how elephant physiological state is influenced by ranging and foraging behavior in human-

501 occupied landscapes. With it, we can begin to identify land use types that are compatible or

502 incompatible with conservation, and establish wildlife corridors to avoid conflict. Due to

503 unpredictable weather patterns, more sampling was carried out during the wet compared to the

504 dry season when conflict with herders is usually more intense, so physiological reactions may

505 have been under estimated. Thus, there is a need for a more comprehensive, multi-year studies to

506 determine how migratory behavior and vegetation changes affect the physiological stress

507 response of both resident and non-resident elephants in the region.

\section{Acknowledgements}

509 We sincerely acknowledge Fardosa Hassan for her support in acquiring research permits and

510 procuring stationery required for the project, and Dr. Dino Martins, Director at Mpala Research

511 Centre and his staff, and the ranch security guards for support of the study. We acknowledge 
512 Margaret Kinnaird, Practice Leader at WWF International for her reviews and comments on

513 earlier versions of the manuscript. We thank Save the Elephant (STE), who funded the Mpala

514 Elephant Monitoring Program between 2009 and 2014 and whose catalogs were used in this

515 study to identify resident and non-resident elephant families. This study was conducted upon

516 request and in collaboration with the Kenya Wildlife Service (KWS) and National Commission

517 for Science and Technology (NACOSTI), who issued the necessary research permits. 
518

519

520

521

522

523

524

525

526

527

528

529

530

531

532

533

534

535

536

537

538

539

540

541

542

543

544

545

546

547

548

549

550

551

552

\section{References}

Ahlering MA, Maldonado JE, Eggert LS, Fleischer RC, Western D, Brown JL. 2013. Conservation outside protected areas and the effect of human-dominated landscapes on stress hormones in savannah elephants. Conservation Biology 27:569-575.

Augustine DJ, McNaughton SJ. 2004. Regulation of shrub dynamics by native browsing ungulates on East African rangeland. Journal of Applied Ecology 41:45-58.

Awuor FO. 2015. Impacts of military training on the distribution and abundance of small versus large wildlife herbivores on Mpala Ranch, Laikipia, Kenya. African Journal of Ecology 53:238-241.

Bale TL, Vale WW. 2004. CRF and CRF receptors: role in stress responsivity and other behaviors. Annual Review of Pharmacology and Toxicology 44:525-557.

Beltran-Abaunza JM. 2009. Method development to process hyper-temporal remote sensing (RS) images for change mapping. Enschede, The Netherlands, University of Twente.

Berger J. 2004. The last mile: how to sustain long-distance migration in mammals. Conservation Biology 18:320-331.

Boettiger AN, Wittemyer G, Starfield R, Volrath F, Douglas-Hamilton I, Getz WM. 2011. Inferring ecological and behavioral drivers of African elephant movement using a linear filtering approach. Ecology 92:1648-1657.

Bradshaw D. 2007. Environmental endocrinology. General and Comparative Endocrinology 152:125-141.

Brown JL, Lehnhardt J. 1995. Serum and urinary hormones during pregnancy and the peri-and postpartum period in an Asian elephant (Elephas maximus). Zoo Biology 14:555-564.

Burnham KP, Anderson DR. 2002. Model Selection and Multimodel Inference: A Practical Information-Theoretic Approach. New York: Springer.

Busch DS, Hayward LS. 2009. Stress in a conservation context: A discussion of glucocorticoid actions and how levels change with conservation-relevant variables. Biological Conservation 142:2844-2853.

Carroll M, DiMiceli C, Sohlberg R, Townshend J. 2004. 250m MODIS normalized difference vegetation index. University of Maryland, College Park, Maryland.

Chamaillé-Jammes S, Mtare G, Makuwe E, Fritz H. 2013. African elephants adjust speed in response to surface-water constraint on foraging during the dry-season. PLOS ONE 8:e59164.

Chase MJ, Schlossberg S, Griffin CR, Bouché PJ, Djene SW, Elkan PW, Ferreira S, Grossman F, Kohi EM, Landen K. 2016. Continent-wide survey reveals massive decline in African savannah elephants. PeerJ 4:e2354. 
553

554

555

556

557

558

559

560

561

562

563

564

565

566

567

568

569

570

571

572

573

574

575

576

577

578

579

580

581

582

583

584

585

586

587

588

Codron J, Lee-Thorp JA, Sponheimer M, Codron D, Grant RC, de Ruiter DJ. 2006. Elephant (Loxodonta africana) diets in Kruger National Park, South Africa: Spatial and landscape differences. Journal of Mammalogy 87:27-34.

Cousins JA, Sadler JP, Evans J. 2008. Exploring the role of private wildlife ranching as a conservation tool in South Africa: stakeholder perspectives. Ecology and Society 13:4361.

Couzin ID. 2006. Behavioral ecology: Social organization in fission-fusion societies. Current Biology 16:R169-R171.

Craigie ID, Baillie JE, Balmford A, Carbone C, Collen B, Green RE, Hutton JM. 2010. Large mammal population declines in Africa's protected areas. Biological Conservation 143:2221-2228.

Creel S, Dantzer B, Goymann W, Rubenstein DR. 2013. The ecology of stress: effects of the social environment. Functional Ecology 27:66-80.

Dantzer B, Fletcher QE, Boonstra R, Sheriff MJ. 2014. Measures of physiological stress: a transparent or opaque window into the status, management and conservation of species? Conservation Physiology 2:cou023.

Denver RJ, Hopkins PM, McCormick SD, Propper CR, Riddiford L, Sower SA, Wingfield JC. 2009. Comparative endocrinology in the 21 st century. Integrative and Comparative Biology 49:339-348.

Dingle H, Drake VA. 2007. What is migration? BioScience 57:113-121.

Douglas-Hamilton I. 1972. On the Ecology and Behaviour of the African Elephant. University of Oxford.

Douglas-Hamilton I, Krink T, Vollrath F. 2005. Movements and corridors of African elephants in relation to protected areas. Naturwissenschaften 92:158-163.

Dublin HT. 1983. Cooperation and reproductive competition among female African elephants. In S Wasser ed, Social Behavior of Female Vertebrates. Academic Press:291-313.

Fahrig L. 2007. Non-optimal animal movement in human-altered landscapes. Functional Ecology 21:1003-1015.

Fanson KV, Keeley T, Fanson BG. 2014. Cyclic changes in cortisol across the estrous cycle in parous and nulliparous Asian elephants. Endocrine Connections 3:57-66.

Figgis P. 2004. Conservation on private lands: the Australian experience: IUCN.

Foley CAH, Papageorge S, Wasser SK. 2001. Noninvasive stress and reproductive measures of social and ecological pressures in free-ranging African elephants. Conservation Biology 15:1134-1142.

Fryxell J, Sinclair A. 1988. Causes and consequences of migration by large herbivores. Trends in Ecology \& Evolution 3:237-241.

Peer) reviewing PDF | (2020:05:48932:1:0:NEW 21 Aug 2020) 
589

590

591

592

593

594

595

596

597

598

599

600

601

602

603

604

605

606

607

608

609

610

611

612

613

614

615

616

617

618

619

620

621

622

623

624

625

626

627

Gallagher AJ, Creel S, Wilson RP, Cooke SJ. 2017. Energy landscapes and the landscape of fear. Trends in Ecology \& Evolution 32:88-96.

Ganswindt A, Brown JL, Freeman EW, Kouba AJ, Penfold LM, Santymire RM, Vick MM, Wielebnowski N, Willis EL, Milnes MR. 2012. International Society for Wildlife Endocrinology: the future of endocrine measures for reproductive science, animal welfare and conservation biology. Biology Letters 8:695-697.

Ganswindt A, Rasmussen HB, Heistermann M, Hodges JK. 2005. The sexually active states of free-ranging male African elephants (Loxodonta africana): defining musth and nonmusth using endocrinology, physical signals, and behavior. Hormones and Behavior 47:83-91.

Gobush KS, Mutayoba BM, Wasser SK. 2008. Long-term impacts of poaching on relatedness, stress physiology, and reproductive output of adult female African elephants. Conservation Biology 22:1590-1599.

Goheen JR, Palmer TM, Charles GK, Helgen KM, Kinyua SN, Maclean JE, Turner BL, Young HS, Pringle RM. 2013. Piecewise disassembly of a large-herbivore community across a rainfall gradient: the UHURU experiment. PLOS ONE 8:e55192.

Goldenberg S, Douglas-Hamilton I, Daballen D, Wittemyer G. 2017. Challenges of using behavior to monitor anthropogenic impacts on wildlife: a case study on illegal killing of African elephants. Animal Conservation 20:215-224.

Goldenberg SZ, Douglas-Hamilton I, Wittemyer G. 2018. Inter-generational change in African elephant range use is associated with poaching risk, primary productivity and adult mortality. Proceedings of the Royal Society B: Biological Sciences 285:20180286.

Graham MD, Douglas-Hamilton I, Adams WM, Lee PC. 2009. The movement of African elephants in a human-dominated land-use mosaic. Animal Conservation 12:445-455.

Gubbi S, Poornesha H, Madhusudan M. 2012. Impact of vehicular traffic on the use of highway edges by large mammals in a South Indian wildlife reserve. Current Science:1047-1051.

Haase CG, Long AK, Gillooly JF. 2016. Energetics of stress: linking plasma cortisol levels to metabolic rate in mammals. Biology Letters 12:20150867.

Hamel S, Garel M, Festa-Bianchet M, Gaillard JM, Côté SD. 2009. Spring Normalized Difference Vegetation Index (NDVI) predicts annual variation in timing of peak faecal crude protein in mountain ungulates. Journal of Applied Ecology 46:582-589.

Harper JM, Austad SN. 2001. Effect of capture and season on fecal glucocorticoid levels in deer mice (Peromyscus maniculatus) and red-backed voles (Clethrionomys gapperi). General and Comparative Endocrinology 123:337-344.

Harvey S, Phillips JG, Rees A, Hall TR. 1984. Stress and adrenal function. Journal of Experimental Zoology 232:633-645.

Hopcraft JGC, Morales JM, Beyer H, Borner M, Mwangomo E, Sinclair A, Olff H, Haydon DT. 2014. Competition, predation, and migration: individual choice patterns of Serengeti migrants captured by hierarchical models. Ecological Monographs 84:355-372.

Peer] reviewing PDF | (2020:05:48932:1:0:NEW 21 Aug 2020) 
628

629

630

631

632

633

634

635

636

637

638

639

640

641

642

643

644

645

646

647

648

649

650

651

652

653

654

655

656

657

658

659

660

661

662

663

664

Huber S, Palme R, Arnold W. 2003. Effects of season, sex, and sample collection on concentrations of fecal cortisol metabolites in red deer (Cervus elaphus). General and Comparative Endocrinology 130:48-54.

Hunninck L, May R, Jackson CR, Palme R, Røskaft E, Sheriff MJ. 2020. Consequences of climate-induced vegetation changes exceed those of human disturbance for wild impala in the Serengeti ecosystem. Conservation Physiology 8:10.1093/conphys/coz117

Hunninck L, Ringstad IH, Jackson CR, May R, Fossøy F, Uiseb K, Killian W, Palme R, Røskaft E. 2017. Being stressed outside the park-conservation of African elephants (Loxodonta africana) in Namibia. Conservation Physiology 5:cox067.

Hunt CE. 1997. Conservation on private lands: an owner's manual: World Wildlife Fund Washington, DC.

Ihwagi FW, Skidmore AK, Wang T, Bastille-Rousseau G, Toxopeus AG, Douglas-Hamilton I. 2019. Poaching lowers elephant path tortuosity: implications for conservation. The Journal of Wildlife Management 83:1022-1031.

Ihwagi FW, Thouless C, Wang T, Skidmore AK, Omondi P, Douglas-Hamilton I. 2018. Night-day speed ratio of elephants as indicator of poaching levels. Ecological Indicators 84:38-44.

Jachowski DS, Kauffman MJ, Jesmer BR, Sawyer H, Millspaugh JJ. 2018. Integrating physiological stress into the movement ecology of migratory ungulates: a spatial analysis with mule deer. Conservation Physiology 6:coy054.

Jachowski DS, Montgomery RA, Slotow R, Millspaugh JJ. 2013. Unravelling complex associations between physiological state and movement of A frican elephants. Functional Ecology 27:1166-1175.

Jachowski DS, Singh NJ. 2015. Toward a mechanistic understanding of animal migration: incorporating physiological measurements in the study of animal movement. Conservation Physiology 3:cov035.

Jachowski DS, Slotow R, Millspaugh JJ. 2012. Physiological stress and refuge behavior by African elephants. PLOS ONE 7:e31818.

Kahindi O, Wittemyer G, King J, Ihwagi F, Omondi P, Douglas-Hamilton I. 2010. Employing participatory surveys to monitor the illegal killing of elephants across diverse land uses in Laikipia-Samburu, Kenya. African Journal of Ecology 48:972-983.

Kartzinel TR, Hsing JC, Musili PM, Brown BR, Pringle RM. 2019. Covariation of diet and gut microbiome in African megafauna. Proceedings of the National Academy of Sciences 116:23588-23593.

Keigwin M, Wabukawo V, Wasser SK, Chapman CA. 2018. Impacts on transboundary elephant movements between Queen Elizabeth Conservation Area, Uganda and Parc National des Virunga, Democratic Republic of Congo. Pachyderm 57:118-121.

Peer) reviewing PDF | (2020:05:48932:1:0:NEW 21 Aug 2020) 
665

666

667

668

669

670

671

672

673

674

675

676

677

678

679

680

681

682

683

684

685

686

687

688

689

690

691

692

693

694

695

696

697

698

699

700

701

702

Kiffner C, Kioko J, Kissui B, Painter C, Serota M, White C, Yager P. 2014. Interspecific variation in large mammal responses to human observers along a conservation gradient with variable hunting pressure. Animal Conservation 17:603-612.

Kinnaird MF, O'brien TG. 2012. Effects of private-land use, livestock management, and human tolerance on diversity, distribution, and abundance of large African mammals. Conservation Biology 26:1026-1039.

Kyale DM, Ngene S, Maingi J. 2011. Biophysical and human factors determine the distribution of poached elephants in Tsavo East National Park, Kenya. Pachyderm 49:48-60.

Lee PC. 1987. Allomothering among African elephants. Animal Behaviour 35:278-291.

Lenth R, Singmann H, Love J, Buerkner P, Herve M. 2018. Emmeans: Estimated marginal means, aka least-squares means. $R$ package version 1:3.

Lima SL, Dill LM. 1990. Behavioral decisions made under the risk of predation: a review and prospectus. Canadian Journal of Zoology 68:619-640.

Lima SL, Zollner PA. 1996. Towards a behavioral ecology of ecological landscapes. Trends in Eology \& Evolution 11:131-135.

Litoroh M, Ihwagi FW, Mayienda R, Bernard J, Douglas-Hamilton I. 2010. Total aerial count of elephants in Laikipia-Samburu ecosystem in November 2008. Kenya Wildlife Service, Nairobi, Kenya.

Loarie SR, van Aarde RJ, Pimm SL. 2009. Elephant seasonal vegetation preferences across dry and wet savannas. Biological Conservation 142:3099-3107.

L.W.F. [Laikipia Wildlife Forum] 2012. A Wildlife Conservation Strategy for Laikipia County. In: Graham MD, (Ed), Laikipia Wildlife Forum, Nanyuki, Kenya.

M'mboroki KG, Wandiga S, Oriaso SO. 2018. Climate change impacts detection in dry forested ecosystem as indicated by vegetation cover change in - Laikipia, of Kenya. Environmental Monitoring and Assessment 190:255.

MacDougall-Shackleton SA, Bonier F, Romero LM, Moore IT. 2019. Glucocorticoids and "stress" are not synonymous. Integrative Organismal Biology 1:obz017.

McComb K, Moss C, Durant SM, Baker L, Sayialel S. 2001. Matriarchs as repositories of social knowledge in African elephants. Science 292:491-494.

McComb K, Shannon G, Durant SM, Sayialel K, Slotow R, Poole J, Moss C. 2011. Leadership in elephants: the adaptive value of age. Proceedings of the Royal Society B: Biological Sciences 278:3270-3276.

McComb K, Shannon G, Sayialel KN, Moss C. 2014. Elephants can determine ethnicity, gender, and age from acoustic cues in human voices. Proceedings of the National Academy of Sciences 111:5433-5438.

Morfeld KA, Lehnhardt J, Alligood C, Bolling J, Brown JL. 2014. Development of a body condition scoring index for female African elephants validated by ultrasound measurements of subcutaneous fat. PLOS ONE 9:e93802.

Peer) reviewing PDF | (2020:05:48932:1:0:NEW 21 Aug 2020) 
703 Moss C. 1996. Getting to know a population. In K Kanwana, ed, Studying Elephants. African Wildlife Fondation, Nairobi, Kenya:58-74.

705

706

707

708

709

710

711

712

713

714

715

716

717

718

719

720

721

722

723

724

725

726

727

728

729

730

731

732

733

734

735

736

737

738

739

740

Moss C, Poole J. 1983. Relationships and social structure of African elephants. In RA Hinde ed, Primate Social Relationships: An Intergrated Approach. Wiley-Blackwell 315:325: 325.

Möstl E, Palme R. 2002. Hormones as indicators of stress. Domestic Animal Endocrinology 23:67-74.

Mumby HS, Mar KU, Thitaram C, Courtiol A, Towiboon P, Min-Oo Z, Htut-Aung Y, Brown JL, Lummaa V. 2015. Stress and body condition are associated with climate and demography in Asian elephants. Conservation Physiology 3:10.1093/conphys/cov030

Munshi-South J, Tchignoumba L, Brown J, Abbondanza N, Maldonado JE, Henderson A, Alonso A. 2008. Physiological indicators of stress in African forest elephants (Loxodonta africana cyclotis) in relation to petroleum operations in Gabon, Central Africa. Diversity and Distributions 14:995-1003.

Nathan R, Getz WM, Revilla E, Holyoak M, Kadmon R, Saltz D, Smouse PE. 2008. A movement ecology paradigm for unifying organismal movement research. Proceedings of the National Academy of Sciences 105:19052-19059.

Ngene S, Mukeka J, Ihwagi F, Mathenge J, Wandera A, Anyona G, Nyumba T, Kawira L, Muthuku I, Kathiwa J. 2013. Total aerial count of elephants, Grevy's zebra and other large mammals in Laikipia-Samburu-Marsabit ecosystem in (November 2012). Kenya Wildlife Service, Nairobi, Kenya.

Ochieng EO. 2015. Characterizing the spatial distributions of elephants in Mpala, Kenya: University of Twente Faculty of Geo-Information and Earth Observation (ITC).

Ogutu JO, Piepho H-P, Reid RS, Rainy ME, Kruska RL, Worden JS, Nyabenge M, Hobbs NT. 2010. Large herbivore responses to water and settlements in savannas. Ecological Monographs 80:241-266.

Omondi P, Bitok E, Mayienda R. 2002. Total aerial count of elephants in Laikipia/Samburu ecosystem, July 2002. Unpublished report Nairobi: Kenya Wildlife Service.

Owen-Smith N, Fryxell J, Merrill E. 2010. Foraging theory upscaled: the behavioural ecology of herbivore movement. Philosophical Transactions of the Royal Society B: Biological Sciences 365:2267-2278.

Parker KL, Barboza PS, Gillingham MP. 2009. Nutrition integrates environmental responses of ungulates. Functional Ecology 23:57-69.

Petorelli N, Ryan S, Mueller T, Bunnefeld N, Jedrzejewska B, Lima M, Kausrud K. 2011. The Normalized Difference Vegetation Index (NDVI) in ecology: a decade of unforseen successes. Clim Res 46:15-27.

Pettorelli N, Vik JO, Mysterud A, Gaillard J-M, Tucker CJ, Stenseth NC. 2005. Using the satellite-derived NDVI to assess ecological responses to environmental change. Trends in Ecology \& Evolution 20:503-510. 
Pokharel S, Singh B, Seshagiri P, Sukumar R. 2019. Lower levels of glucocorticoids in crop-raiders: diet quality as a potential 'pacifier'against stress in free-ranging Asian elephants in a human-production habitat. Animal Conservation 22:177-188.

Pokharel SS, Seshagiri PB, Sukumar R. 2017. Assessment of season-dependent body condition scores in relation to faecal glucocorticoid metabolites in free-ranging Asian elephants. Conservation Physiology 5:cox 039.

Pokharel SS, Seshagiri PB, Sukumar R. 2020. Influence of the number of calves and lactating adult females in a herd on the adrenocortical activity of free-ranging Asian elephants. Wildlife Research 46:679-689.

Polansky L, Douglas-Hamilton I, Wittemyer G. 2013. Using diel movement behavior to infer foraging strategies related to ecological and social factors in elephants. Movement Ecology 1:13.

Polansky L, Kilian W, Wittemyer G. 2015. Elucidating the significance of spatial memory on movement decisions by African savannah elephants using state-space models. Proceedings of the Royal Society B: Biological Sciences 282:20143042.

Pontzer H, Kamilar JM. 2009. Great ranging associated with greater reproductive investment in mammals. Proceedings of the National Academy of Sciences 106:192-196.

Pringle RM. 2008. Elephants as agents of habitat creation for small vertebrates at the patch scale. Ecology 89:26-33.

Purdon A, Mole MA, Chase MJ, Van Aarde RJ. 2018. Partial migration in savanna elephant populations distributed across southern Africa. Scientific Reports 8:11331.

Purdon A, Van Aarde R. 2017. Water provisioning in Kruger National Park alters elephant spatial utilisation patterns. Journal of Arid Environments 141:45-51.

R Development Core Team. 2018. R: A language and environment for statistical computing; 2015.

Ranaweerage E, Ranjeewa ADG, Sugimoto K. 2015. Tourism-induced disturbance of wildlife in protected areas: A case study of free ranging elephants in Sri Lanka. Global Ecology and Conservation 4:625-631.

Rasmussen HB, Ganswindt A, Douglas-Hamilton I, Vollrath F. 2008. Endocrine and behavioral changes in male African elephants: linking hormone changes to sexual state and reproductive tactics. Hormones and Behavior 54:539-548.

Ripple WJ, Newsome TM, Wolf C, Dirzo R, Everatt KT, Galetti M, Hayward MW, Kerley GI, Levi T, Lindsey PA. 2015. Collapse of the world's largest herbivores. Science Advances 1:e1400103.

Rolandsen CM, Solberg EJ, Sæther B-E, Moorter BV, Herfindal I, Bjørneraas K. 2017. On fitness and partial migration in a large herbivore - migratory moose have higher reproductive performance than residents. Oikos 126:547-555. 
778

779

780

781

782

783

784

785

786

787

788

789

790

791

792

793

794

795

796

797

798

799

800

801

802

803

804

805

806

807

808

809

810

811

812

813

814

815

Romero LM, Wingfield JC. 2015. Tempests, poxes, predators, and people: stress in wild animals and how they cope: Oxford University Press.

Sach F, Dierenfeld ES, Langley-Evans SC, Watts MJ, Yon L. 2019. African savanna elephants (Loxodonta africana) as an example of a herbivore making movement choices based on nutritional needs. PeerJ 7:e6260.

Sapolsky RM, Romero LM, Munck AU. 2000. How do glucocorticoids influence stress responses? Integrating permissive, suppressive, stimulatory, and preparative actions. Endocrine Reviews 21:55-89.

Shaw AK, Couzin ID. 2013. Migration or residency? The evolution of movement behavior and information usage in seasonal environments. The American Naturalist 181:114-124.

Sheriff MJ, Dantzer B, Delehanty B, Palme R, Boonstra R. 2011. Measuring stress in wildlife: techniques for quantifying glucocorticoids. Oecologia 166:869-887.

Soares MC, Bshary R, Fusani L, Goymann W, Hau M, Hirschenhauser K, Oliveira RF. 2010. Hormonal mechanisms of cooperative behaviour. Philosophical Transactions of the Royal Society B: Biological Sciences 365:2737-2750.

Soltis J, King LE, Douglas-Hamilton I, Vollrath F, Savage A. 2014. African elephant alarm calls distinguish between threats from humans and bees. PLOS ONE 9:e89403.

Stabach J, Boone R, Worden J, Florant G. 2015. Habitat disturbance effects on the physiological stress response in resident Kenyan white-bearded wildebeest (Connochaetes taurinus). Conservation Biology 182:177-186.

Stankowich T. 2008. Ungulate flight responses to human disturbance: A review and metaanalysis. Conservation Biology 141:2159-2173.

Strack AM, Sebastian RJ, Schwartz MW, Dallman MF. 1995. Glucocorticoids and insulin: reciprocal signals for energy balance. American Journal of Physiology-Regulatory, Integrative and Comparative Physiology 268:R142-R149.

Sundaresan SR, Riginos C. 2010. Lessons learned from biodiversity conservation in the private lands of Laikipia, Kenya. Great Plains Research:17-27.

Szott ID, Pretorius Y, Ganswindt A, Koyama NF. 2020. Physiological stress response of African elephants to wildlife tourism in Madikwe Game Reserve, South Africa. Wildlife Research 47:34-43.

Szott ID, Pretorius Y, Koyama NF. 2019. Behavioural changes in African elephants in response to wildlife tourism. Journal of Zoology 308:164-174.

Tarakini T, Crosmary W-G, Fritz H, Mundy P. 2014. Flight behavioural responses to sport hunting by two African herbivores. South African Journal of Wildlife Research 44:76-83, 78.

Taylor D, Lane P, Muiruri V, Ruttledge A, McKeever RG, Nolan T, Kenny P, Goodhue R. 2005. Mid-to late-Holocene vegetation dynamics on the Laikipia Plateau, Kenya. The Holocene 15:837-846.

Peer) reviewing PDF | (2020:05:48932:1:0:NEW 21 Aug 2020) 
816 Thouless C. 1993. Laikipia Elephant Project Final Report. Unpublished report to Kenya Wildlife $817 \quad$ Service.

818 Thouless C, Dublin HT, Blanc J, Skinner D, Daniel T, Taylor R, Maisels F, Frederick H, 819 Bouche P. 2016. African elephant status report 2016. An update from the African Elephant $820 \quad$ Database.

821

822

823

824

825

826

827

828

829

830

831

832

833

834

835

836

837

838

839

840

841

842

843

844

845

846

847

848

849

850

851

852

853

Thouless CR. 1996. Home ranges and social organization of female elephants in northern Kenya. African Journal of Ecology 34:284-297.

Tingvold HG, Fyumagwa R, Bech C, Baardsen LF, Rosenlund H, Røskaft E. 2013. Determining adrenocortical activity as a measure of stress in African elephants (Loxodonta africana) in relation to human activities in Serengeti ecosystem. African Journal of Ecology 51:580-589.

Vidya T, Thuppil V. 2010. Immediate behavioural responses of humans and Asian elephants in the context of road traffic in southern India. Biological Conservation 143:1891-1900.

Vijayakrishnan S, Kumar MA, Umapathy G, Kumar V, Sinha A. 2018. Physiological stress responses in wild Asian elephants Elephas maximus in a human-dominated landscape in the Western Ghats, southern India. General and Comparative Endocrinology:150-156.

Viljoen JJ, Ganswindt A, Palme R, Reynecke HC, Du Toit JT, Langbauer Jr WR. 2008. Measurement of concentrations of faecal glucocorticoid metabolites in free-ranging African elephants within the Kruger National Park. Koedoe 50:18-21.

Wadey J, Beyer HL, Saaban S, Othman N, Leimgruber P, Campos-Arceiz A. 2018. Why did the elephant cross the road? The complex response of wild elephants to a major road in Peninsular Malaysia. Biological Conservation 218:91-98.

Wasser SK, Hunt KE, Brown JL, Cooper K, Crockett CM, Bechert U, Millspaugh JJ, Larson S, Monfort SL. 2000. A generalized fecal glucocorticoid assay for use in a diverse array of nondomestic mammalian and avian species. General and Comparative Endocrinology 120:260-275.

Watson R, Munro C, Edwards KL, Norton V, Brown JL, Walker SL. 2013. Development of a versatile enzyme immunoassay for non-invasive assessment of glucocorticoid metabolites in a diversity of taxonomic species. General and Comparative Endocrinology 186:16-24.

Webber JT, Henley MD, Pretorius Y, Somers MJ, Ganswindt A. 2018. Changes in African Elephant (Loxodonta africana) faecal steroid concentrations post-defaecation. BothaliaAfrican Biodiversity \& Conservation 48:1-8.

Western D, Groom R, Worden J. 2009. The impact of subdivision and sedentarization of pastoral lands on wildlife in an African savanna ecosystem. Biological Conservation 142:25382546.

Wilcove DS, Wikelski M. 2008. Going, going, gone: is animal migration disappearing. PLoS Biology 6:e188. 
854

855

856

857

858

859

860

861

862

863

864

865

866

867

868

869

870
Wingfield JC, Maney DL, Breuner CW, Jacobs JD, Lynn S, Ramenofsky M, Richardson RD. 1998. Ecological bases of hormone-behavior interactions: the "emergency life history stage". American Zoologist 38:191-206.

Wittemyer G, Douglas-Hamilton I, Getz WM. 2005. The socioecology of elephants: analysis of the processes creating multitiered social structures. Animal Behaviour 69:1357-1371.

Wittemyer G, Keating LM, Vollrath F, Douglas-Hamilton I. 2017. Graph theory illustrates spatial and temporal features that structure elephant rest locations and reflect risk perception. Ecography 40:598-605.

Wittemyer G, Northrup JM, Blanc J, Douglas-Hamilton I, Omondi P, Burnham KP. 2014. Illegal killing for ivory drives global decline in African elephants. Proceedings of the National Academy of Sciences 111:13117-13121.

Young TP, Okello B, Kinyua D, Palmer TM. 1997. KLEE: A long-term multi-species herbivore exclusion experiment in Laikipia, Kenya. African Journal of Range \& Forage Science 14:94-102.

Young TP, Patridge N, Macrae A. 1995. Long-term glades in acacia bushland and their edge effects in Laikipia, Kenya. Ecological Applications 5:97-108. 
Figure 1

Annual mean 2019 NDVI base layer map of Mpala Ranch, Laikipia, Kenya showing where fecal samples were collected.

The map shows the distribution of fecal samples collection during the study period and where military trainings are conducted.

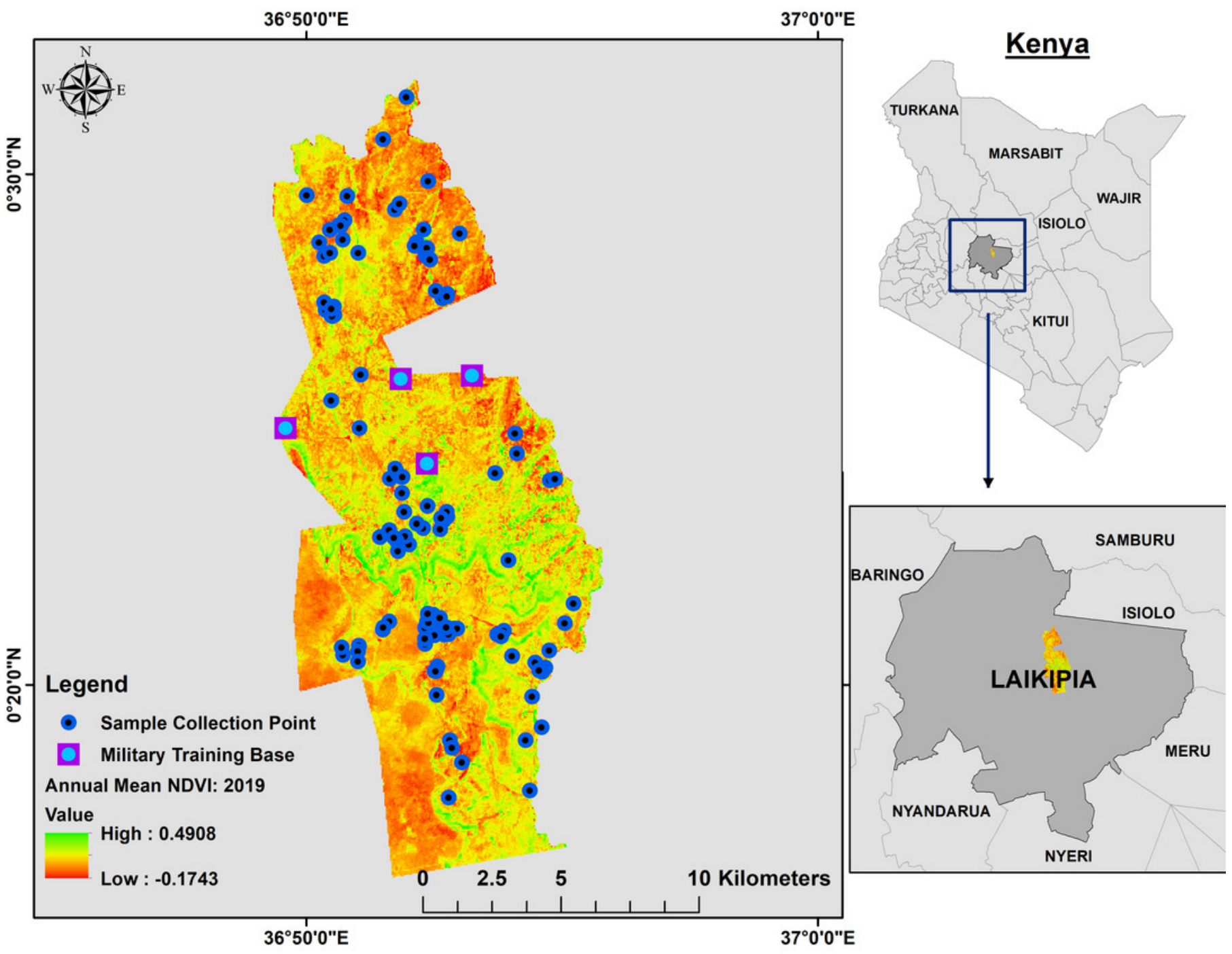




\section{Figure 2}

Linear regression between FGM concentrations and NDVI with fitted data points.

Linear regression model plot with the $95 \%$ confidence interval (grey areas) showing the relationship between back transformed predicted fecal glucocorticoid metabolite (FGM) concentrations and the normalized difference vegetation index (NDVI) with fitted data points.

Predicted FGM (ng/g) represents back transformed values of log FGM from the model.

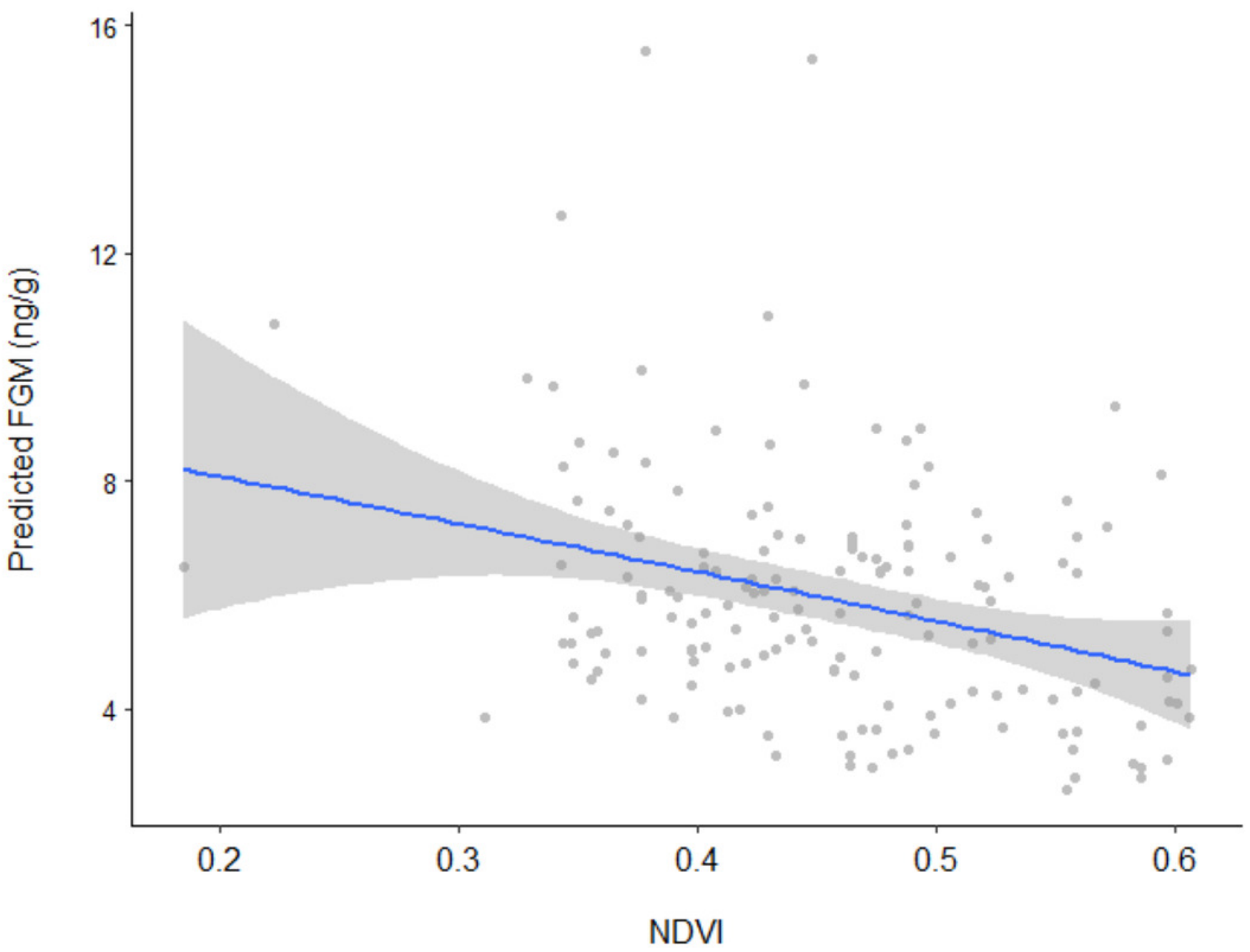




\section{Table $\mathbf{1}$ (on next page)}

Summary of study elephants at Mpala Ranch.

Demographic summary of elephants in the study monitored through behavior and fecal glucocorticoid metabolite (FGM) analyses from April to August 2019 at Mpala Ranch, Laikipia County, Kenya. 
1 Table 1. Summary of study elephants at Mpala Ranch. Demographic summary of elephants

2 in the study monitored through behavior and fecal glucocorticoid metabolite (FGM) analyses

3 from April to August 2019 at Mpala Ranch, Laikipia County, Kenya.

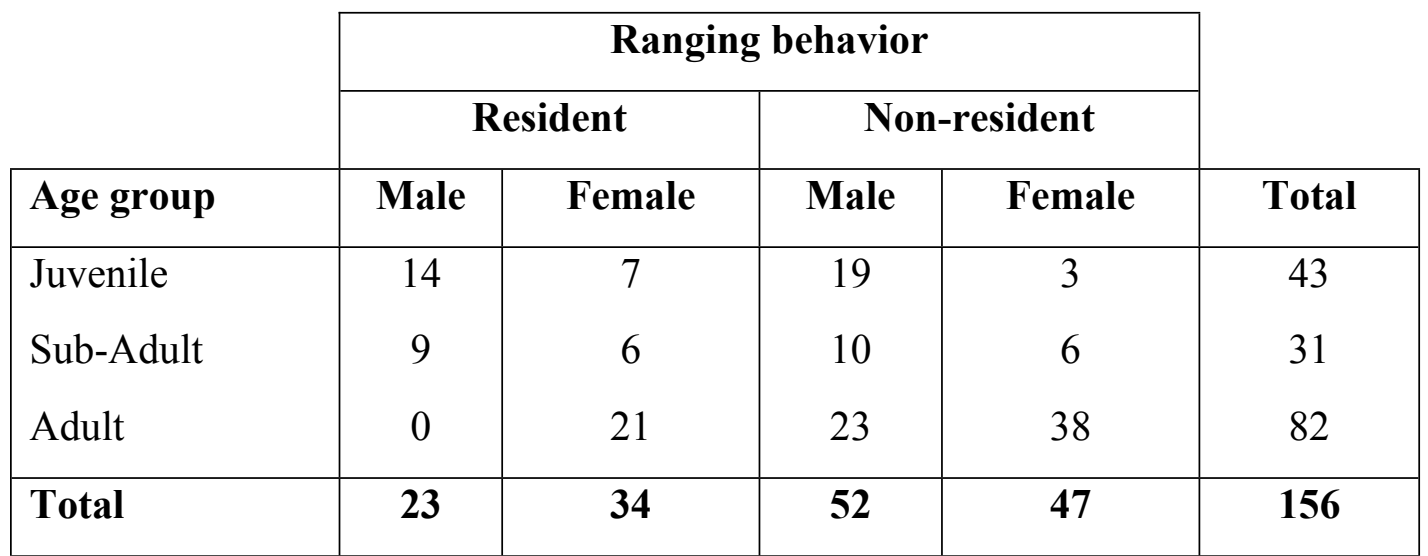

4

5

6

7

8

9

10

11 


\section{Table 2(on next page)}

Model selection based on the basic model and other factors influencing FGM concentrations in African elephants sampled at Mpala Ranch between April and August 2019.

The models consisting of age group and group type were better fit than the basic model (in bold). 
Table 2. Model selection based on the basic model and other factors influencing FGM concentrations in African elephants sampled at Mpala Ranch between April and August 2019. The models consisting of age group and group type were better fit than

3 the basic model (in bold).

\begin{tabular}{|c|c|c|c|c|c|c|c|}
\hline Model & $\mathbf{K}$ & \begin{tabular}{|c|} 
Model \\
Likelihood \\
\end{tabular} & AICc & $\triangle \mathrm{AICc}$ & Weight & $\mathbf{R}^{2}$ & Adj. $R^{2}$ \\
\hline FGM $\sim$ Ranging behavior + Reaction Index + NDVI + Age group & 8 & -32.50 & 81.98 & 0.00 & 0.41 & 0.2347 & 0.2038 \\
\hline FGM $\sim$ Ranging behavior + Reaction Index + NDVI + Group type & 8 & -32.97 & 82.92 & 0.94 & 0.25 & 0.2300 & 0.2000 \\
\hline FGM $\sim$ Ranging behavior + Reaction Index + NDVI & 6 & -35.97 & 84.51 & 2.53 & 0.12 & 0.1998 & 0.1786 \\
\hline FGM $\sim$ Ranging behavior + Reaction Index + NDVI + Sex & 7 & -35.02 & 84.79 & 2.81 & 0.10 & 0.2096 & 0.1832 \\
\hline FGM $\sim$ Ranging behavior + Reaction Index + NDVI + herd size & 7 & -35.80 & 86.36 & 4.38 & 0.05 & 0.2016 & 0.1750 \\
\hline FGM $\sim$ Ranging behavior + Reaction Index + NDVI + Time delay & 7 & -35.81 & 86.38 & 4.40 & 0.05 & 0.2015 & 0.1749 \\
\hline FGM $\sim$ Ranging behavior + Reaction Index + NDVI + BCS & 8 & -35.07 & 87.11 & 5.13 & 0.03 & 0.2091 & 0.1772 \\
\hline
\end{tabular}




\section{Table 3(on next page)}

Results from model-averaged coefficients showing parameter estimates from the basic model and the two competing models.

The predictor variables included ranging behavior, reaction index and the Normalized Difference Vegetation Index (NDVI) age group and group type for elephants at Mpala Ranch. 
Table 3. Results from model-averaged coefficients showing parameter estimates from the basic model and the two competing models. The predictor variables included ranging behavior, reaction index and the Normalized Difference Vegetation Index (NDVI) age group and group type for elephants at Mpala Ranch.

\begin{tabular}{|c|c|c|c|c|c|c|c|c|c|}
\hline & \multicolumn{3}{|c|}{ Model 1} & \multicolumn{3}{|c|}{ Model 2} & \multicolumn{3}{|c|}{ Model 3} \\
\hline Coefficients & Estimates & $\begin{array}{c}\text { Conf. Int. } \\
(95 \%)\end{array}$ & $\begin{array}{c}P- \\
\text { Value }\end{array}$ & Estimates & $\begin{array}{c}\text { Conf. Int. } \\
(95 \%)\end{array}$ & $\begin{array}{c}P- \\
\text { Value }\end{array}$ & Estimates & $\begin{array}{c}\text { Conf. Int. } \\
(95 \%)\end{array}$ & $\begin{array}{c}P- \\
\text { Value }\end{array}$ \\
\hline (Intercept) & 2.31 & $2.00-2.62$ & $<0.001$ & 2.33 & $1.99-2.66$ & $<0.001$ & 2.32 & $2.01-2.62$ & $<0.001$ \\
\hline Ranging behavior [Resident] & 0.12 & $0.00-0.23$ & 0.04 & 0.09 & $-0.02-0.21$ & 0.12 & 0.15 & $0.04-0.26$ & 0.01 \\
\hline $\begin{array}{l}\text { Reaction Index [Retreating } \\
\text { on vehicle approach] }\end{array}$ & -0.04 & $-0.17-0.09$ & 0.52 & -0.04 & $-0.17-0.09$ & 0.56 & -0.03 & $-0.16-0.10$ & 0.60 \\
\hline $\begin{array}{l}\text { Reaction Index [Running } \\
\text { away on vehicle approach] }\end{array}$ & 0.15 & $0.01-0.30$ & 0.04 & 0.14 & $-0.00-0.29$ & 0.05 & 0.15 & $0.01-0.29$ & 0.04 \\
\hline NDVI & -1.44 & $-2.07--0.82$ & $<0.001$ & -1.5 & $-2.12--0.88$ & $<0.001$ & -1.36 & $-1.98--0.74$ & $<0.001$ \\
\hline Social group type [Cow/calf] & & & & 0.06 & $-0.12-0.23$ & 0.53 & & & \\
\hline Social group type [Mixed] & & & & -0.09 & $-0.27-0.10$ & 0.36 & & & \\
\hline Age group [Juvenile] & & & & & & & -0.11 & $-0.23-0.01$ & 0.06 \\
\hline Age group [Sub-Adult] & & & & & & & -0.15 & $-0.28--0.02$ & 0.02 \\
\hline Observations & & 156 & & & 156 & & & 156 & \\
\hline $\mathrm{R}^{2} / \mathrm{R}^{2}$ adjusted & & $0.200 / 0.179$ & & & $0.230 / 0.199$ & & & $0.235 / 0.204$ & \\
\hline
\end{tabular}

